\title{
Assess the knowledge, utilization, level of satisfaction of utilization and barriers of non-utilization regarding Integrated Child Development Services (ICDS) among women of Ernakulam District, Kerala, India
}

\author{
Preethy Jawahar ${ }^{a, *}$, Sudha A. Raddi ${ }^{b}$ \\ ${ }^{\text {a }}$ Dept. of Community Health Nursing, M.O.S.C. College of Nursing, Kolenchery, Kerala, India \\ ${ }^{\mathrm{b}}$ Faculty of Nursing, KLEU Institute of Nursing Sciences, Belgaum, Karnataka, India
}

\section{A R T I C L E I N F O}

\section{Keywords:}

Knowledge

Utilization

Satisfaction

Barriers

ICDS

Women

\begin{abstract}
A B S T R A C T
Introduction: The integrated child development scheme (ICDS) was launched in 1975 to provide an integrated package of services to aid the holistic development of the child. The beneficiaries of this scheme are children below the age of six, pregnant and lactating women in the age group of 15-45 years.

Objectives: The objectives of the present study were to assess the knowledge, utilization, level of satisfaction of utilization and barriers of non-utilization regarding Integrated Child Development Services (ICDS) among women.

Methods: This study adopted a quantitative approach using a descriptive survey design. Convenience sampling technique was used to collect data from 553 women between the age group of 18-45 years residing in Ernakulam district, Kerala, India. Five tools were used to collect the data. The obtained data from 553 women entered in data sheet using SPSS version 20 and was analyzed by using descriptive statistics.

Results: Majority women (68.5\%) had average knowledge regarding ICDS services. Mothers who had under five children utilized more ICDS services $(90.5 \%)$ compared to pregnant women $(48.7 \%)$ and lactating mothers (27.2\%). Majority women (75\%) were highly satisfied with utilization of ICDS services. The first and foremost barrier for non-utilization of ICDS services among women was lack of time due to work (60\%).

Conclusion: The ICDS programme is a globally recognized community based programme, which addresses the basic interrelated needs of young children and mothers, in a holistic manner.
\end{abstract}

\section{Introduction}

India is home for the largest child population in the world. The development of children is the first priority of the country's agenda, not because they are the most vulnerable, but because they are our supreme assets and also the future human resources of the country. As per the Tenth Five Year Plan (2002-07), the future of India depends on the future of Indian child population. The first six years in a child's life is crucial as the foundations for cognitive, social, emotional, physical, motor and psychological developments are laid during this stage. Child survival, growth and development can be achieved adequately through a holistic approach. Between education, health and nutrition, there is necessity for a balanced link between education, health and nutrition, which is essential for the proper development of a child. It is now globally acknowledged that investment in human resources development is a pre-requisite for economic development of any nation. As per an Indian census conducted in 2011, there is approximately 163.81 million children below the age of six out of which many doesn't still have access to proper health care, nutrition, sanitation, child care, early stimulation, etc.

The integrated child development scheme was launched in 1975 to provide an integrated package of services to aid the holistic development of the child. The beneficiaries of this scheme are children below the age of six, pregnant and lactating women in the age group of 15-45 years. The aim of the scheme is to improve the nutritional and health status of vulnerable groups by providing a package of services which includes preschool education, immunization, supplementary nutrition, health checkup, referral services and health education. ICDS is a multisectoral program and involves several government departments. The ICDS services are coordinated at the village, block, district, state and

\footnotetext{
* Corresponding author.

E-mail address: preethymosc@gmail.com (P. Jawahar).
} 
central government levels. These services are provided through community based anganwadi centres. ${ }^{2}$

A significant number of these children survive in an economic and social environment which hinders or delays the child's physical and mental development. The contributing factors include poverty, poor environmental sanitation, diseases, infections, inadequate access to primary health care, inappropriate child caring, feeding practices etc. Fact is that these lives can be improved with better child care facilities. The main goal of ICDS program is to improve the nutrition and health status of children, antenatal women, postnatal mothers, other women and adolescent girls through direct intervention mechanism. ${ }^{4}$

Mother is a primary care provider and therefore her education and access to information will help her in caring her infant. As children constitute the most important and vulnerable segment of our population, the mothers is the most important health worker as far as child health is concerned. The mothers play a major role in promoting the health of children below the age of five and child care activities. Child care includes knowledge regarding prevention of childhood diseases, proper growth, development and basic needs of the children. The mother is the key person in the family who promotes the child's wellbeing to prevent diseases. The mother will get information regarding child care through health care professionals, family members, neighbors, and mass media. ${ }^{9}$

The investigator noted that only a few number of children are coming to the centre regularly and utilizing the services. It was noted that ICDS services were not fully utilized by the mothers with children below the age of five because of lack of knowledge on ICDS services. So the investigator felt the need to assess the knowledge, utilization, level of satisfaction of utilization and barriers of non-utilization regarding ICDS among women. The improvement of knowledge related to ICDS services will help the mothers to involve positively and utilize the ICDS services adequately. The mother's positive approach will bring healthier children to the nation. The strength of the nation depends on healthy families and children who are destined to be successful citizens of tomorrow. ${ }^{12}$

\section{Methods}

\subsection{Study design}

This study adopted a quantitative approach using a descriptive survey design.

\subsection{Setting and Participants}

The study setting was women residing in Ernakulam district, Kerala, India. Data was collected from 553 women between the age group of 18-45 years residing in Ernakulam district, Kerala, India.

\subsection{Inclusion and exclusion criteria}

Convenience sampling technique was used to collect data. Inclusion criteria were primi and multi gravida women, lactating mothers between 0 to 6 months, mothers who were having at least one living child below five years of age and between the age group of 18-45 years were included. Women who were not willing and not available during the time of data collection and women who were not able to speak or understand Malayalam were excluded.

\subsection{Data collection tools}

The tools used were Tool 1: Demographic proforma, Tool 2: Structured questionnaire to assess the knowledge on ICDS Services, Tool 3: Checklist to identify the utilization of ICDS services, Tool 4: Satisfaction scale to find the level of satisfaction regarding the utilization of ICDS services and Tool 5: Checklist to assess the barriers of non-utilization on
ICDS services. The content validity of the five tools were obtained by submitting the tools to 11 experts in the field of medicine and nursing. Tools were translated to Malayalam and retranslated to English by a language expert. Structured interview schedule was used to collect the data. Pretesting of the tools were done by administering the tools to 5 women to determine the clarity of the items, presence of ambiguous terms, time required and the feasibility of the tools. Tools were administered to 20 women to determine the reliability by test-retest method. The reliability co-efficient (r) value of tools were 0.92 (tool 2), 0.96 (tool 3), 0.88 (tool 4) and 0.93 (tool 5) respectively.

\subsection{Pilot study}

Pilot study data was conducted to assess the feasibility and study was found to be feasible.

\subsection{Data collection procedure}

Main data collection was done among 553 women. Data was collected from February 1, 2017 to June 30, 2017. Administrative permission from the concerned authorities was taken. Permission was obtained from Institutional Ethical Committee (IEC) and District Medical Officer, Ernakulam District. Written consent was taken from women.

\subsection{Details of data analysis}

The obtained data from 553 women entered in data sheet using SPSS version 20 and data was analyzed for all the objectives by using descriptive statistics (Measures of frequency like frequency \& percentage and Measures of central tendency like mean \& standard deviation). Descriptive statistics was the useful method to summarize the survey data and responses.

\section{Results}

\subsection{Description of sample characteristics}

As shown in Table 1, majority women i.e. $40.7 \%$ belonged to the age group of 26-30 years, all women were married (100\%), majority women $(58.2 \%)$ were having diploma level of education, $58 \%$ women were housewives, $72 \%$ women belonged to nuclear family and $53.7 \%$ women were Christians.

As shown in Fig. 1, out of 553 women, 78 (14\%) women were pregnant and remaining $475(86 \%)$ were not pregnant. Out of 553 women, $66(12 \%)$ were lactating mothers and remaining 487 (88\%) were not lactating mothers. Out of 553 women, 542 (98\%) women had under five children. Remaining 11 (2\%) women had no children and they were primigravidas. Women were mutually inclusive in all the three groups (pregnant women, lactating mothers and women who had under five children).

\subsection{Description of knowledge score of women regarding ICDS services}

The structured knowledge questionnaire regarding ICDS services was administered to 553 women to assess their knowledge. The knowledge scores were categorized as poor (1-10), average (11-20) and good (21-30) based on arbitrary method. The maximum score was 30 .

As shown in Table 2, 28\% women had good knowledge, $68.5 \%$ women had average knowledge and $3.5 \%$ women had poor knowledge. Out of a total score of 30 , the mean and standard deviation of total knowledge score were 18 and 4 respectively.

\subsection{Description of utilization of ICDS services}

Data was collected from 553 women using a structured questionnaire regarding utilization of ICDS services. As shown in Fig. 2, among 
Table 1

Description of sample characteristics of women in terms of frequency and percentage $(n=553)$.

\begin{tabular}{|c|c|c|c|}
\hline SI. No & Socio-demographic variables & Frequency (f) & Percentage (\%) \\
\hline \multirow[t]{6}{*}{1} & Age in years & & \\
\hline & $18-25$ & 97 & 17.50 \\
\hline & $26-30$ & 225 & 40.70 \\
\hline & $31-35$ & 188 & 34.00 \\
\hline & $36-40$ & 43 & 07.80 \\
\hline & $41-45$ & 00 & 00.00 \\
\hline \multirow[t]{2}{*}{2} & Marital status & & \\
\hline & Married & 553 & 100 \\
\hline \multirow[t]{7}{*}{3} & Education & & \\
\hline & Upto 9th standard & 49 & 08.80 \\
\hline & SSLC & 16 & 02.80 \\
\hline & Plus Two & 12 & 02.10 \\
\hline & Diploma & 322 & 58.20 \\
\hline & Graduate & 98 & 17.70 \\
\hline & Post graduate and above & 56 & 10.40 \\
\hline \multirow[t]{6}{*}{4} & Occupation & & \\
\hline & House wife & 321 & 58.00 \\
\hline & Coolie worker & 13 & 02.35 \\
\hline & Unprofessional & 109 & 19.70 \\
\hline & Professional & 106 & 19.10 \\
\hline & Student & 04 & 00.85 \\
\hline \multirow[t]{3}{*}{5} & Type of family & & \\
\hline & Nuclear & 398 & 72.00 \\
\hline & Joint & 155 & 28.00 \\
\hline \multirow[t]{4}{*}{6} & Religion & & \\
\hline & Christians & 297 & 53.70 \\
\hline & Hindus & 242 & 43.90 \\
\hline & Muslims & 14 & 02.40 \\
\hline
\end{tabular}

pregnant women utilized $48.7 \%$ ICDS services from the anganwadi, lactating mothers utilized 27.2\% ICDS services from the anganwadi and mothers who had under five children utilized 90.5\% ICDS services from the anganwadi. Mothers who had under five children utilized more ICDS services (90.5\%) compared to pregnant women (48.7\%) and lactating mothers (27.2\%).
Result of item analysis showed that, among pregnant women, $44 \%$ utilized supplementary nutrition from the anganwadi centres, $25 \%$ pregnant women utilized health and nutrition education from the anganwadi centres, $100 \%$ pregnant women utilized TT immunization from the government centres and private hospitals and none from the anganwadi centres, $15 \%$ pregnant women utilized health checkup from the anganwadi centres, $5 \%$ pregnant women utilized referral services from the anganwadi centres and 7\% pregnant women utilized iron and folic acid tablets given from the anganwadi centres. Among lactating mothers, $10 \%$ utilized supplementary nutrition from the anganwadi centres, $43 \%$ lactating mothers utilized health and nutrition education from the anganwadi centres, 4\% lactating mothers utilized health checkup and referral services (weight checking) from the anganwadi centres. Among mothers who had under five children utilized $80 \%$ supplementary nutrition from the anganwadi centres, $76 \%$ mothers who had under five children utilized non formal education from the anganwadi centres, all children (100\%) were immunized up to the age and immunizations were taken from government centres or private hospitals. 78\% mothers who had under five children utilized pulse polio and vitamin A immunizations from the anganwadi centres, 65\% mothers who had under five children utilized health checkup (height and weight checking) from anganwadi centres.

\subsection{Level of satisfaction in utilization regarding ICDS services}

Out of 553 women, 498 utilized atleast one service from the ICDS and 55 did not utilize any service from ICDS. By using satisfaction scale, data related to level of satisfaction of utilization regarding ICDS services

Table 2

Frequency and percentage distribution, mean and standard deviation (SD) of total knowledge score $(\mathrm{n}=553)$.

\begin{tabular}{lllllll}
\hline $\begin{array}{l}\text { SI. } \\
\text { No }\end{array}$ & $\begin{array}{l}\text { Knowledge } \\
\text { category }\end{array}$ & $\begin{array}{l}\text { Range of } \\
\text { score }\end{array}$ & $\begin{array}{l}\text { Frequency } \\
\text { (f) }\end{array}$ & $\begin{array}{l}\text { Percentage } \\
(\%)\end{array}$ & Mean & SD \\
\hline 1 & Poor & $1-10$ & 19 & 03.50 & & \\
2 & Average & $11-20$ & 379 & 68.50 & 18 & 4 \\
3 & Good & $21-30$ & 155 & 28.00 & & \\
\hline
\end{tabular}

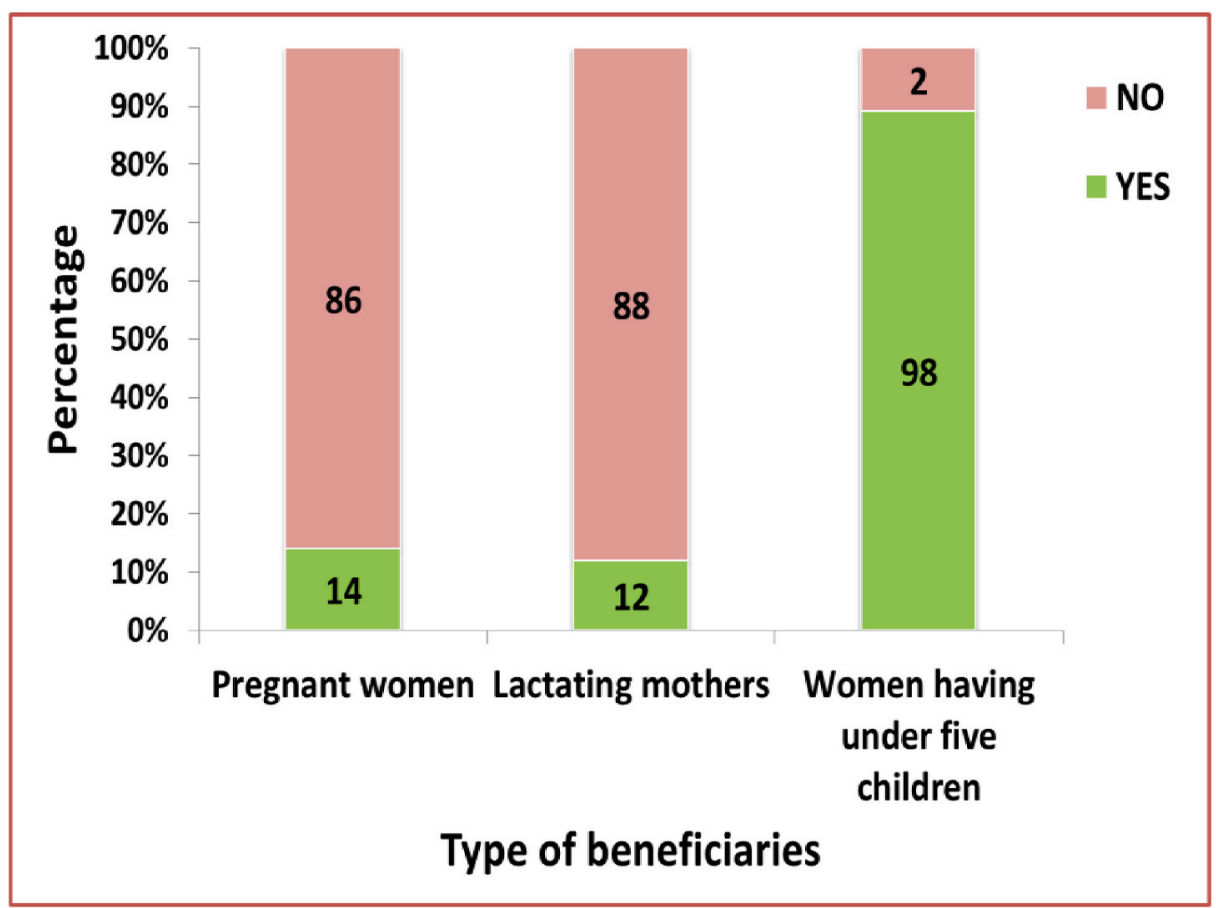

Fig. 1. Bar graph showing percentage distribution of women based on type of beneficiaries $(n=553)$. 


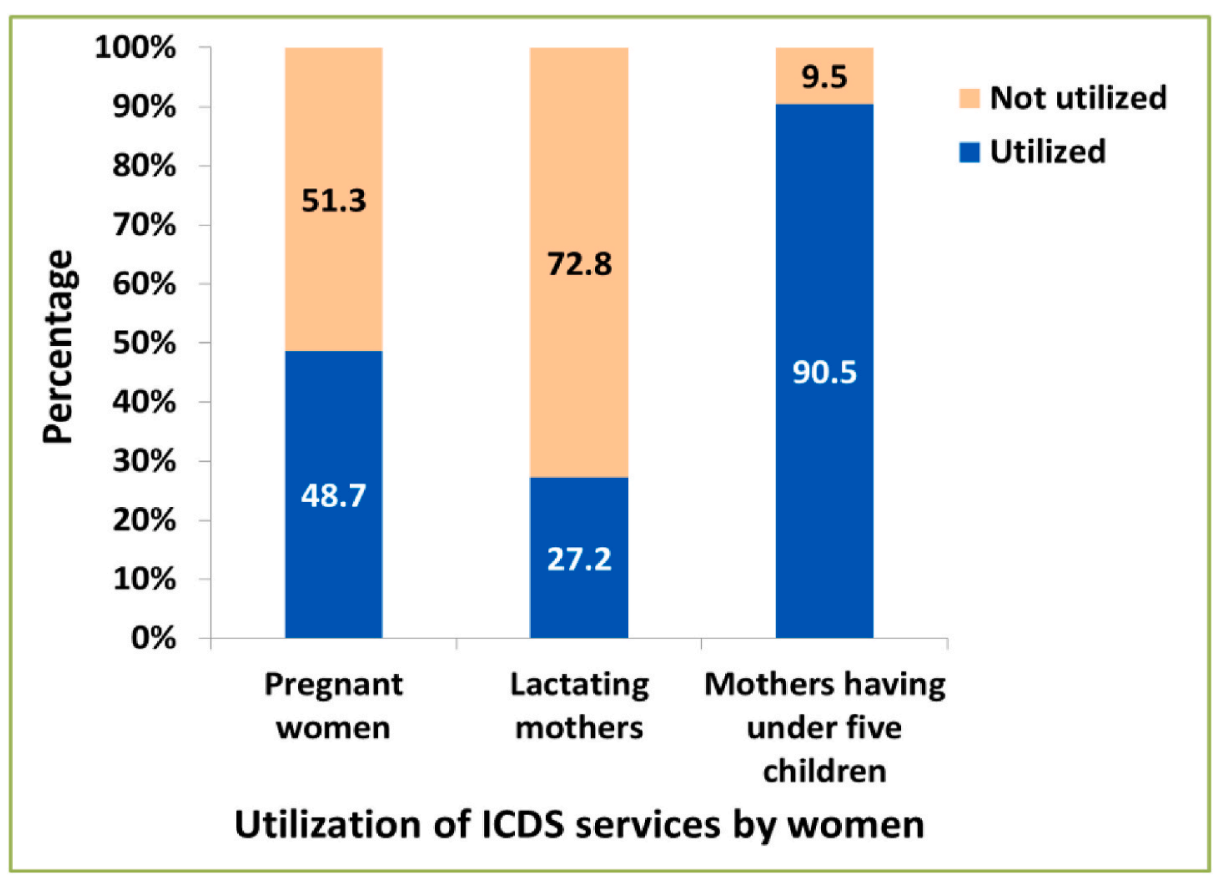

Fig. 2. Bar graph showing the percentage of utilization of ICDS services by women $(n=553)$.

were collected from 498 women who utilized any one of the ICDS services from the anganwadi centres. It is evident from Table 3 that, majority of women (75\%) were highly satisfied with the utilization of ICDS services from the anganwadi centres.

Result of item analysis showed that, majority women were satisfied with the facilities and infrastructure available in the anganwadi. $75 \%$ women were highly satisfied with the quality of the food supplied through the anganwadi, 85\% women were highly satisfied with preschool education given to children between 3 to 6 years, $60 \%$ women were highly satisfied with the health checkup, referral services and growth monitoring services provided in the anganwadi, $56 \%$ women were highly satisfied with the immunization services provided by the anganwadi workers, $88 \%$ women were highly satisfied with the cleanliness of the anganwadi, $81 \%$ women were highly satisfied with the knowledge, skill and expertise of the anganwadi workers, $66 \%$ women were highly satisfied with attitude of the anganwadi workers, $82 \%$ women were highly satisfied with the behaviour of the anganwadi workers and $90 \%$ women were highly satisfied with the timings of anganwadi workers.

\subsection{Barriers of non-utilization of ICDS services}

Out of 553 women, 55 women did not utilize any of the ICDS services from the anganwadi and their barriers of non-utilization regarding ICDS services was assessed using a checklist. The barriers for non-utilization of ICDS services by the women from the anganwadi included that they were not able to spare much time due to work (60\%), no proper

\section{Table 3}

Frequency and percentage distribution, mean and standard deviation (SD) of satisfaction score $(n=498)$.

\begin{tabular}{lllllll}
\hline $\begin{array}{l}\text { SI. } \\
\text { No }\end{array}$ & $\begin{array}{l}\text { Categories of } \\
\text { satisfaction }\end{array}$ & $\begin{array}{l}\text { Range of } \\
\text { score }\end{array}$ & $\begin{array}{l}\text { Frequency } \\
\text { (f) }\end{array}$ & $\begin{array}{l}\text { Percentage } \\
(\%)\end{array}$ & Mean & SD \\
\hline 1 & $\begin{array}{l}\text { Extremely } \\
\text { dissatisfied }\end{array}$ & $20-39$ & 0 & 0 & & \\
& Dissatisfied & $40-59$ & 0 & 0 & 86 & 5 \\
2 & Satisfied & $60-79$ & 124 & 25 & & \\
4 & Highly & $80-100$ & 374 & 75 & & \\
\hline
\end{tabular}

communication by anganwadi workers (45\%), behavior of anganwadi workers were not good (33\%), distance from anganwadi to home (32\%), lack of knowledge (24\%), family members were not interested to avail anganwadi services (12\%). Notion that the services are meant for the poor $(10 \%)$ and anganwadi workers never organize meetings regularly $(2 \%)$.

\section{Discussion}

The present study revealed that $28 \%$ women had good knowledge, $68.5 \%$ women had average knowledge and $3.4 \%$ women had poor knowledge. Mothers who had under five children utilized more ICDS services $(90.5 \%)$ compared to pregnant women (48.7\%) and lactating mothers (27.2\%). $75 \%$ women were highly satisfied with utilization of ICDS services from the AWC and $25 \%$ women were satisfied with the utilization of ICDS services from the AWC. The barriers for nonutilization of ICDS services included not being able to spare much time due to work (60\%), lack of proper communication by anganwadi workers (45\%) and unacceptable behavior of anganwadi workers (33\%).

The present study finding is parallel to the findings of Kumar D et al. ${ }^{4}$ Low levels of awareness regarding TT immunization (74.2\%), five-cleans (31.9\%), post-natal care (75.4\%) among lactating mothers. Knowledge regarding optimal infant and young child feeding practices was poor. Initiation of breast-feeding within six hours (17.4\%), colostrum feeding (34.8\%) and exclusive breastfeeding (5.8\%). High levels of awareness regarding reproductive health parameters (81.6\%), legal ages at marriages for girls $(84.5 \%)$, desired birth interval of three or more years $(71.7 \%){ }^{4}$

The present study finding is similar to the findings of Chudasama RK et al. ${ }^{11}$ Results showed that majority of pregnant (94.7\%) and lactating (74.4\%) mothers were availing ICDS services. ${ }^{11}$ The present study finding is in line to the findings of Lal S. ${ }^{13}$ Health checkup utilized by children less than 5 years increased from $28.2 \%$ to $92 \%$ and those of pregnant and lactating mothers increased from $18.7 \%$ to $38 \%$. Supplementary nutrition utilized by children less than 5 years of age increased from $8 \%$ to $50 \%$ and that of pregnant and lactating mothers increased from $0 \%$ to $25 \%$. Immunization utilized by pregnant mothers increased from $1 \%$ to $50 \%$. $^{13}$

The finding from the present study is not parallel to the findings of 
Davey A et al. ${ }^{7} 52.5 \%$ mothers were dissatisfied with the services provided from the AWC for one or more reason. The most common reasons for dissatisfaction were poor accessibility of the AWC, cramped space at the AWC (68.6\%), poor quality of the food distributed (66.7\%) and irregular preschool education (57.1\%) from AWCs. ${ }^{7}$ The present study findings found no similarity with the work of Chattopadhyay D. ${ }^{8}$ The Result showed that mothers were dissatisfied with the services provided from the AWC. ${ }^{8}$

The work of Davey A et al. ${ }^{7}$ confirmed the present study findings. Most of the barriers mentioned was the not easy accessibility of the AWC and less space available at the AWC (68.6\%), followed by the poor quality of the food distributed (66.7\%) and irregular preschool education (57.1\%) from AWCs. ${ }^{7}$ The present study finding is similar to the findings of Kapil V et al. ${ }^{10}$ The major reasons for not utilizing ICDS services reported by mothers were the difficulties in carrying the child to the anganwadi centres and inadequate contact of the anganwadi workers with the mother. ${ }^{10}$

\section{Conclusion}

The Integrated Child Development Scheme is a globally recognized community programme based on early child care which addresses the basic interrelated needs of young children, antenatal and lactating mothers in a holistic manner. This programme is a response to the challenge of breaking a vicious cycle of impaired development, malnutrition, morbidity and mortality of under-five children. ICDS has made important contributions to child development in India. In our country with a wide variation in needs, resources and management, wide variations in performance levels ranging from successes at one end to failures at the other, are to be expected. Health professionals, administrators and politicians have obligations towards the children of their country. They must continue to contribute to the effective implementation of ICDS in our country. Accurate information and encouragement from anganwadi workers and health personnel's will help to improve their knowledge and utilization of ICDS services.

Strength

Cost effective and gather information from 553 women.

\section{Limitations}

Lack of depth while collecting data.

\section{Declaration}

Ethical approval

Obtained.

Funding

This research did not receive any specific grant from funding agencies.

\section{Conflict of interest}

Authors declare that there is no conflict of interest.

\section{Acknowledgement}

None.

\section{References}

1 Sachdev Y, Dasgupta J. Integrated child development services (ICDS) scheme. Med J Armed Forces India. 2001 Apr 1;57(2):139-143.

2 Gupta A. Governing population: the integrated child development services program in India. States of imagination: ethnographic explorations of the postcolonial state. $2001 \mathrm{Dec}$ 12:65-96.

4 Kumar D, Goel NK, Kalia M, Swami HM, Singh R. Gap between awareness and practices regarding maternal and child health among women in an urban slum community. Indian J Pediatr. 2008 May 1;75(5):455-458.

7 Davey A, Davey S, Datta U. Perception regarding quality of services in urban ICDS blocks in Delhi. Indian J Publ Health. 2008 Jul 1;52(3):156-158.

8 Chattopadhyay D. Knowledge and skills of anganwadi workers in Hooghly district, West Bengal. Indian J Community Med. 2004;29(3):4.

9 Datta V, John R, Singh VP, Chaturvedi P. Maternal knowledge, attitude and practices towards diarrhea and oral rehydration therapy in rural Maharashtra. Indian J Pediatr. 2001 Nov 1;68(11):1035-1037.

10 Kapil V, Nayar D, Nandan D. Reasons of under utilization of integrated child development services by children under three years of age. Indian J Matern Child Health. 1996;7(4):102-103.

11 Chudasama RK, Patel UV, Kadri AM, Mitra A, Thakkar D, Oza J. Evaluation of integrated child development services program in Gujarat, India for the years 2012 to 2015. Indian J Publ Health. 2016 Apr 1;60(2):124.

12 Kapil U, Pradhan R. Integrated child development services scheme (ICDS) in India: its activities, present status and future strategy to reduce malnutrition. J Indian Med Assoc. 2000 Sep 1;98(9):559-560.

13 Lal S. Better primary health care services utilization through integrated child development service scheme in Haryana. Indian J Pediatr. 1980 Jul 1;47(4):293-296. 